\title{
Suppression of UV-induced apoptosis by the human DNA repair protein XPG
}

\author{
V Clément ${ }^{1,2}$, I Dunand-Sauthier ${ }^{1}$ and SG Clarkson ${ }^{\star, 1}$ \\ 1 Department of Microbiology and Molecular Medicine, University Medical \\ Centre (CMU), Geneva, Switzerland \\ ${ }^{2}$ Current address: Department of Genetic Medicine and Development, \\ University Medical Centre (CMU), 1 rue Michel-Servet, 1211 Geneva 4, \\ Switzerland \\ * Corresponding author. SG Clarkson, Department of Microbiology and \\ Molecular Medicine, University Medical Centre (CMU), 1 rue Michel-Servet, \\ 1211 Geneva 4, Switzerland. Tel: + 4122-379-5664; Fax: + 4122-379-5702; \\ E-mail: stuart.clarkson@medecine.unige.ch
}

Received 26.4.05; revised 07.7.05; accepted 01.8.05; published online 16.9.05 Edited by $\mathrm{K}$ Vousden

\section{Abstract}

The severe xeroderma pigmentosum/Cockayne syndrome (XP/CS) syndrome is caused by mutations in the XPB, XPD and XPG genes that encode the helicase subunits of TFIIH and the $3^{\prime}$ endonuclease of nucleotide excision repair (NER). Because XPB and XPD have been implicated in p53-mediated apoptosis, we examined the possible involvement of XPG in this process. After ultraviolet light (UV) irradiation, primary fibroblasts of XP complementation group G (XP-G) individuals with CS enter apoptosis more readily than other NER-deficient cells, but this is unlinked to unrepaired damage. These XP-G/ CS cells accumulate $\mathrm{p} 53$ post-UV but they fail to accumulate the $90 / 92 \mathrm{kDa}$ isoforms of Mdm2 and their cellular distribution of Mdm2 is impaired. Apoptosis levels revert to wild type, Mdm2 $90 / 92 \mathrm{kDa}$ isoforms accumulate, and Mdm2 regains its normal post-UV nuclear location in transduced XP-G/CS cells expressing wild-type XPG, but not an XPG catalytic site mutant. These results suggest that XPG suppresses UVinduced apoptosis and that this suppression, most simply, requires its endonuclease function.

Cell Death and Differentiation (2006) 13, 478-488.

doi:10.1038/sj.cdd.4401764; published online 16 September 2005

Keywords: apoptosis; Mdm2; p53; UV; XPG

Abbreviations: 6-4PPs, (6-4) pyrimidine-pyrimidone photoproducts; CPDs, cyclobutane pyrimidine dimers; CS, Cockayne syndrome; NER, nucleotide excision repair; UV, ultraviolet light; $X P$, xeroderma pigmentosum; XP-G, patients or cells of patients belonging to $\mathrm{XP}$ complementation group $\mathrm{G}$

\section{Introduction}

UV sunlight is an important source of mutagenic lesions among which cyclobutane pyrimidine dimers (CPDs) and (6-4) pyrimidine-pyrimidone photoproducts (6-4PPs) are the most prevalent. Human cells use three strategies to protect genomic DNA from accumulating such lesions. If the UV damage is slight, DNA repair is attempted. If the damage is more extensive, cell cycle progression is blocked to allow more time for DNA repair. If the damage is so extensive as to be irreparable within an acceptable time frame, the affected cells undergo apoptosis. ${ }^{1,2}$

UV damage is removed by nucleotide excision repair (NER), a highly conserved DNA repair pathway that involves $\sim 30$ proteins in humans. These are involved in successive steps of DNA damage recognition, local unwinding of the DNA around the lesion, dual incision of the damaged DNA strand, release of a short lesion-containing oligonucleotide, then gap filling and ligation of the newly synthesised DNA. NER removes UV damage, and other bulky lesions, from transcriptionally inert regions of the genome and from the nontranscribed strand of active genes. ${ }^{1}$ A subpathway of NER that shares many of its components is known as transcription-coupled NER (TC-NER). This removes damage preferentially from the transcribed DNA strand of actively expressed genes. ${ }^{3}$

The induction of cell cycle arrest or apoptosis critically depends on the tumour-suppressor p53. In unstressed cells, the steady-state level of this transcription factor is low through Mdm2-dependent proteasomal degradation. ${ }^{4,5}$ After DNA damage, p53 is modified at specific residues leading to its accumulation in the nucleus where it activates the transcription of several downstream genes, including $B A X, p 21$ and MDM2. ${ }^{5,6}$ The products of such p53-inducible genes then initiate cascades of events that result in DNA repair, cell cycle arrest or apoptosis.

Our current view of apoptosis has been greatly helped by analyses of human cells with mutations in NER genes leading to the recessive disorders xeroderma pigmentosum (XP) and Cockayne syndrome (CS). Both syndromes share an extreme photosensitivity but, unlike XP patients, CS individuals do not have an elevated risk of skin cancer. ${ }^{7}$ CS is caused by mutations in the CSA or CSB genes and they result in defective TC-NER. The outcome is more varied for mutations in the seven XP genes (XPA-XPG) implicated in NER. Mutant $X P C$ and XPE proteins disrupt NER but not TC-NER, whereas mutant proteins from $X P$ groups $A, B, D, F$ and $G$ lead to defective NER and TC-NER. ${ }^{1}$

The $X P B$ and $X P D$ genes encode the helicase subunits of the transcription/repair factor TFIIH, whereas XPG codes for the endonuclease that cuts the damaged DNA strand $3^{\prime}$ to the lesion during NER. ${ }^{1}$ Nevertheless, these three genes, when mutated in particular ways, give rise to the rare XP/CS disorder, in which the severe neurological features of CS overlay many XP symptoms. ${ }^{7,8}$

Overexpression of p53 leads to elevated levels of apoptosis in normal human fibroblasts, but not in XP-B or XP-D fibroblasts. ${ }^{9}$ This effect can be reversed by expression of the wild-type $X P B$ or $X P D$ gene in the relevant mutant cells. These results have led to the suggestion that XPB and XPD are components of a p53-mediated apoptotic pathway. ${ }^{9}$ 
Evidence conflicts, however, on the response of XP-B and XP-D cells to DNA damage. For example, it has been reported that XP-D lymphocytes are more resistant than normal to adriamycin-induced apoptosis, ${ }^{9}$ whereas XP-B and XP-D fibroblasts are hypersensitive to UV-induced apoptosis. ${ }^{10,11}$

To date, there have been no reports of the apoptotic response of XPG-deficient human cells. Given the XP/CS connection between certain XP-B, XP-D and XP-G patients, we have performed a detailed examination of UV-induced apoptosis in primary fibroblasts from mildly affected XP-G and severely affected XP-G/CS individuals. Our results suggest that the human XPG protein normally suppresses UV-induced apoptosis.

\section{Results}

\section{XP-G/CS fibroblasts enter UV-induced apoptosis more readily than other NER-deficient cells}

To avoid cellular artefacts produced by viral immortalisation, we examined UV-induced apoptosis in primary cells at low passage number. Wild-type primary fibroblasts were compared with their counterparts from patients from the following repair-deficient complementation groups: XP-C (deficient in NER), CS-A and CS-B (deficient in TC-NER), and XP-A, $X P-G$ and XP-G/CS (deficient in both NER and TC-NER). The fibroblasts were exposed to various UVC doses and their apoptotic response was measured $72 \mathrm{~h}$ later by AnnexinV/ propidium iodide $(\mathrm{PI})$ staining.

Little apoptosis $(<7 \%)$ was detected in wild-type cells exposed up to $20 \mathrm{~J} / \mathrm{m}^{2}$; apoptosis was more extensive at higher doses, reaching $\sim 30 \%$ at $50 \mathrm{~J} / \mathrm{m}^{2}$ (Figure 1a). XP-C primary fibroblasts had a similar apoptotic response. CS-A and CS-B fibroblasts behaved like wild-type and XP-C cells up
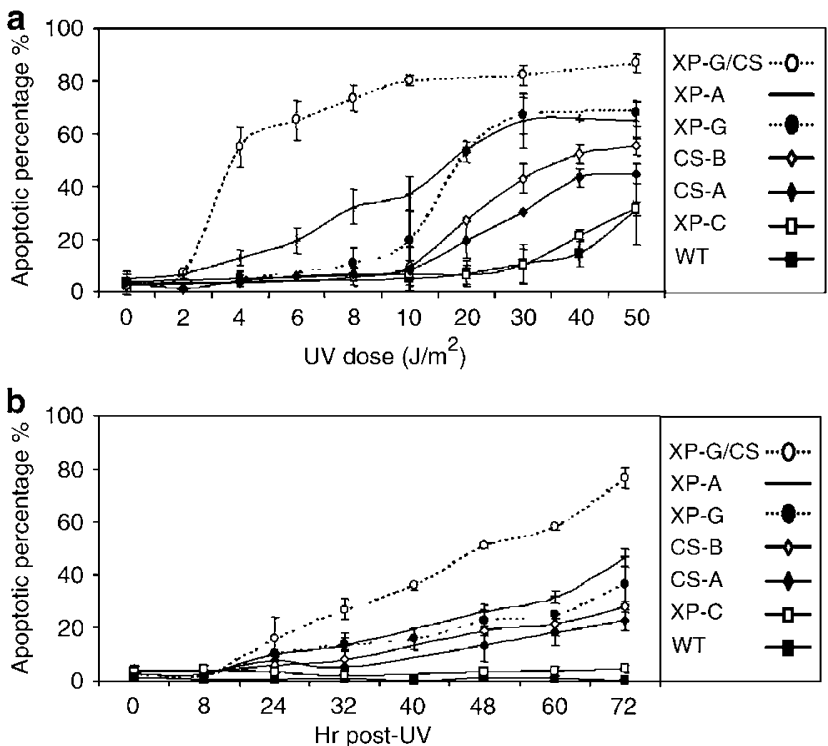

Figure $1 \mathrm{XP}-\mathrm{G} / \mathrm{CS}$ cells are very susceptible to UV-induced apoptosis. (a) Primary fibroblasts were irradiated with the indicated UVC doses and the extent of apoptosis was determined $72 \mathrm{~h}$ later by the annexin V-FITC/PI assay. (b) Apoptosis was measured at the indicated times following a UVC dose of $20 \mathrm{~J} / \mathrm{m}^{2}$ to $10 \mathrm{~J} / \mathrm{m}^{2}$, but at higher doses they became much more UV sensitive (Figure 1a).

The most severe effects were found with XP-A, XP-G and XP-G/CS cells. At low UV doses, XP-A fibroblasts entered apoptosis more readily than those from a mildly affected XP-G individual, but at higher doses $\left(\geq 20 \mathrm{~J} / \mathrm{m}^{2}\right)$ they displayed no differences (Figure 1a). Fibroblasts from XP-G/CS patient XPCS2RO also exhibited a similar dose-response from $\geq 20 \mathrm{~J} / \mathrm{m}^{2}$ but at lower doses they entered apoptosis more readily than XP-A cells (data not shown). Fibroblasts from XPG/CS patient XP20BE were even more susceptible to UV, exhibiting apoptotic levels of $\sim 50 \%$ at $4 \mathrm{~J} / \mathrm{m}^{2}$ and $>80 \%$ at $10 \mathrm{~J} / \mathrm{m}^{2}$ (Figure 1a). For all primary fibroblasts studied, necrosis was negligible $\left(<5 \%\right.$ even after $50 \mathrm{~J} / \mathrm{m}^{2}$, data not shown).

To determine if these repair-deficient primary fibroblasts enter apoptosis with different kinetics, we treated them with a fixed UVC dose of $20 \mathrm{~J} / \mathrm{m}^{2}$ and followed their apoptotic response over time using AnnexinV/PI staining. Very little apoptosis was detected $8 \mathrm{~h}$ post-UV for any of the fibroblasts, and apoptotic levels remained low (3-5\%) for wild-type and XP-C cells even after $72 \mathrm{~h}$ (Figure $1 \mathrm{~b}$ ). Apoptosis gradually increased with time from $24 \mathrm{~h}$ for CS-A, CS-B, XP-A and XP-G cells, with the $C S$ cells being less severely affected than $X P-A$ or XP-G cells. XP-G/CS fibroblasts from patient XP20BE were again the most severely affected: $\sim 15 \%$ had died by apoptosis $24 \mathrm{~h}$ post-UV, and close to $80 \%$ at $72 \mathrm{~h}$ (Figure 1b), consistent with the dose-response curve (Figure 1a). These results were independently confirmed by the TUNEL assay (data not shown). Hence, XP-G/CS fibroblasts can enter apoptosis more rapidly and at lower UV doses than other NER-deficient fibroblasts.

\section{Complementation of primary fibroblasts with lentiviral recombinants}

To determine if the apoptotic response in XPG-deficient cells is due to the inactivity or absence of the XPG protein, we transduced them with XPG cDNAs in a lentiviral vector. To avoid XPG overexpression, the cDNAs were placed under the control of the relatively weak EF $1 \alpha$ promoter. The transduced cells were amplified for $\geq 10$ days before analyses of XPG protein levels and UV-induced apoptosis.

Immunoblots with an anti-XPG monoclonal antibody revealed a weak XPG band in cell extracts from the mildly affected XP-G patient XP125LO (Figure 2a). This band represents the product of her maternal $X P G$ allele containing a single amino-acid substitution in the endonuclease active site. ${ }^{12}$ This band remained unchanged after transduction with the empty lentiviral vector (Figure 2a). No XPG protein was found in cell extracts of XP-G/CS patient XP20BE before or after transduction with the empty lentiviral vector (Figure $2 \mathrm{a}$ ). However, after transduction with the wild-type XPG lentiviral recombinant, both XP-G and XP-G/CS cells expressed correct length XPG in amounts comparable to the endogenous level (Figure 2a).

Apoptosis was then assayed by AnnexinV/PI staining $72 \mathrm{~h}$ postirradiation. At all UVC doses tested, XP-G/CS fibroblasts transduced with the empty vector were more resistant to 
apoptosis than untransduced XP-G/CS cells (Figure 2b). As $X P G$ is not detectable in these cells (Figure 2a), this surprising result cannot represent partial complementation by XPG. Instead, we suspect that it reflects the selection of a more robust subpopulation of cells that were able to better withstand lentiviral transduction. More important, XP-G/CS cells expressing wild-type XPG were as resistant to apoptosis as wild-type fibroblasts transduced with the empty vector (Figure 2b). Wild-type XPG also fully complemented XP-G fibroblasts (data not shown). These results strongly suggest that the extreme sensitivity of XP-G/CS cells to UV-induced apoptosis (Figure 1) is due to the inactivity or absence of the XPG protein. Its important corollary is that XPG normally suppresses apoptosis following UV damage.

a

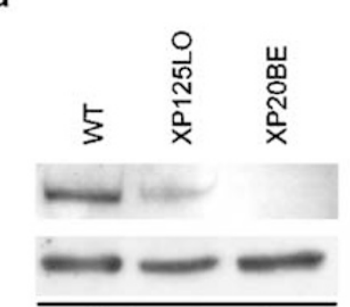

Untransduced

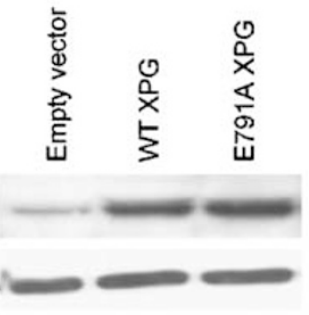

Transduced XP-G
$X P G$

tubulin

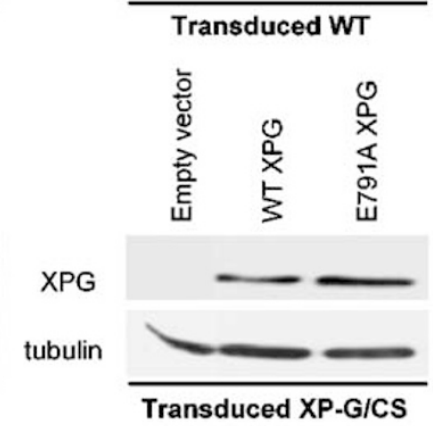

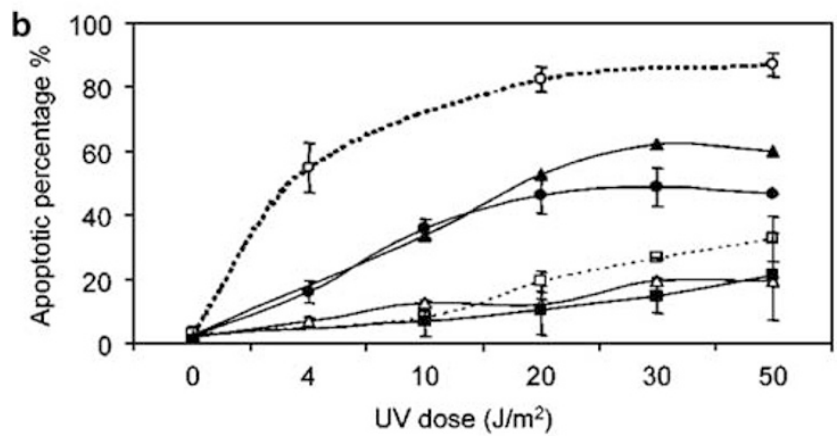

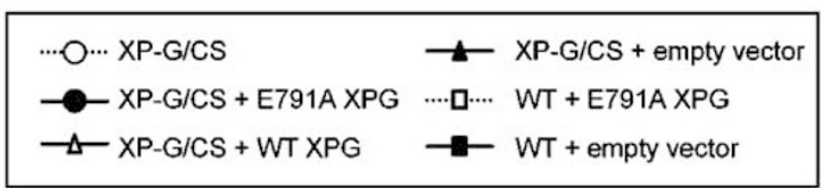

Figure 2 Wild-type XPG, but not a catalytic site mutant, restores normal levels of UV-induced apoptosis in transduced XP-G/CS cells. (a) Equal quantities of protein from untransduced cells and transductants containing the indicated lentiviral constructs were analysed by Western blotting with antibodies to XPG and tubulin (as loading control). (b) The transductants were irradiated with increasing doses of UVC and apoptosis was quantified $72 \mathrm{~h}$ later by annexinV/PI staining
Next, we transduced wild-type and XPG-deficient fibroblasts with a lentiviral recombinant expressing the E791A catalytic site mutant of XPG. This protein was also expressed in the transductants in amounts comparable to wild-type XPG (Figure 2a). E791A XPG has no $3^{\prime}$ endonuclease activity in $\mathrm{NER}^{12}$ and, when expressed in wild-type cells, it competes with the endogenous XPG for stable recruitment to UV damage sites, thereby making the cells more UV sensitive. ${ }^{13}$ Consistent with these results, wild-type transductants expressing E791A XPG entered apoptosis more readily than those transduced with the empty vector (Figure $2 \mathrm{~b}$ ). XP-G/CS cells transduced with the E791A recombinant or empty vector were much more UV sensitive and displayed identical levels of apoptosis up to $10 \mathrm{~J} / \mathrm{m}^{2}$ (Figure 2b). At higher doses transductants expressing the catalytic site mutant were slightly more UV resistant than the empty vector transductants but were far short of the full complementation found with wildtype XPG (Figure 2b). Possible reasons for this difference are considered in the Discussion.

\section{Apoptosis levels do not simply correlate with the extent of unrepaired DNA damage}

To examine the possible correlation between apoptotic levels and lesion density, we exposed the repair-deficient fibroblasts to $20 \mathrm{~J} / \mathrm{m}^{2}$ and isolated genomic DNA $0-72 \mathrm{~h}$ later. DNA samples were then probed in an immunoslot blot assay ${ }^{14}$ with monoclonal antibodies to the two major types of UV damage, CPDs and 6-4PPs. Loss of immunoreactivity over time is taken to mean that these lesions have been repaired, predominantly by NER rather than TC-NER.

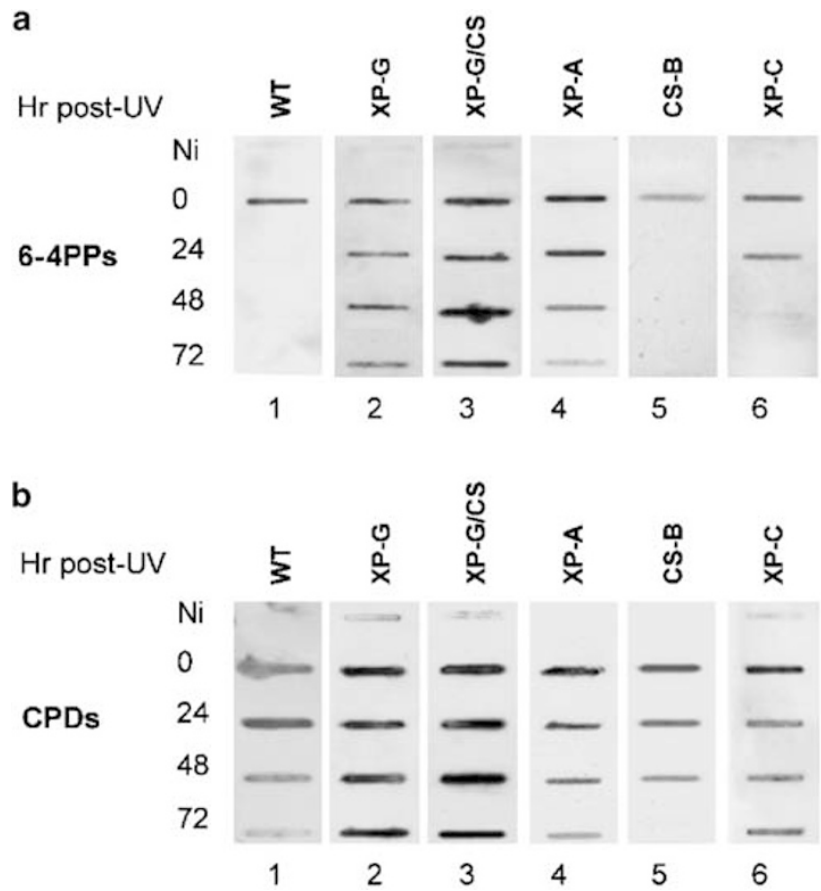

Figure 3 Levels of unrepaired DNA damage in UV-irradiated primary fibroblasts. The indicated fibroblasts were irradiated with a UVC dose of $20 \mathrm{~J} /$ $\mathrm{m}^{2}$ and the subsequent retention of DNA damage was analysed by immunoslot blotting with antibodies to (a) 6-4PPs and (b) CPDs. $\mathrm{Ni}=$ nonirradiated 
6-4PPs were repaired much faster than CPDs in wild-type fibroblasts (Figures $3 a$ and $b$, lane 1), as expected from previous work. ${ }^{15}$ In CS-B fibroblasts, 6-4PPs were also removed within $24 \mathrm{~h}$ post-UV (Figure $3 \mathrm{a}$, lanes 1 and 5 ). They were repaired more slowly in XP-C fibroblasts and some 6-4PPs were found at $48 \mathrm{~h}$ (Figure $3 \mathrm{a}$, lane 6). They persisted up to $72 \mathrm{~h}$ in XP-A cells, although the signal intensity decreased with time (Figure $3 a$, lane 4). In contrast, the levels of 6-4PPs remained essentially unchanged in XP-G and $X P-G / C S$ cells, indicating that these lesions were not repaired in these XPG-deficient cells (Figure 3a, lanes 2 and 3).

CPDs were removed in a similar manner but less efficiently. Thus, wild-type and CS-B fibroblasts removed CPDs with comparable kinetics (Figure $3 \mathrm{~b}$, lanes 1 and 5), XP-A and $\mathrm{XP}-\mathrm{C}$ cells retained CPD lesions up to $72 \mathrm{~h}$ post-UV (Figure $3 \mathrm{~b}$, lanes 4 and 6), and very little if any CPD repair occurred in XP-G and XP-G/CS cells (Figure 3b, lanes 2 and 3 ).

The repair characteristics of these fibroblasts (Figure 3 ) are not easily reconciled with their apoptotic behaviour (Figure 1). For UV-induced apoptosis, wild-type and XP-C cells behave identically yet XP-C cells retain damage longer. Conversely, CS-B cells enter apoptosis more readily but retain less UV damage than XP-C cells. XP-A and XP-G cells exhibit similar apoptotic behaviour yet the XP-A cells appear to have some repair activity, although more vigorous replication of these XPA cells may have contributed to the dilution of the signals with time. Finally, XP-G and XP-G/CS fibroblasts retain comparable amounts of UV damage yet XP-G/CS cells are much more susceptible to UV-induced apoptosis. Persistence of global UV damage clearly contributes to the severity of the apoptotic response in these fibroblasts, and the nonrepair of 6-4PPs appears to be particularly important. However, these results demonstrate that apoptosis levels do not correlate in a simple way with the extent of unrepaired DNA damage. This is consistent with much earlier work suggesting that apoptosis levels correlate better with the persistence of unrepaired lesions in transcribed DNA. ${ }^{11,16-18}$ Clearly, it will be of interest to examine the XP-G and XP-G/CS cells for potential differences in TC-NER and/or transcription. For the moment, the important novel conclusion is that the exquisite sensitivity of XP-G/CS cells to UV-induced apoptosis is not simply due to their retention of more DNA damage than other repairdeficient cells.

\section{p53 accumulates rapidly and strongly in XPG- deficient fibroblasts after UV irradiation}

To examine the potential involvement of p53 in UV-induced apoptosis in these cells, we measured by immunoblotting p53 steady-state levels at various times after a UVC dose of $20 \mathrm{~J} /$ $\mathrm{m}^{2}$. The same was performed for other repair-deficient and wild-type fibroblasts. In wild-type cells, p53 accumulated from 3 to $12 \mathrm{~h}$ post-UV, then slightly dropped at $24 \mathrm{~h}$ (Figure $4 \mathrm{a}$ and b). XP-C cells behaved similarly but accumulated $\sim 2$-fold more p53. CS-B and XP-G also exhibited similar kinetics initially but p53 levels then continued to increase with time (Figure $4 \mathrm{a}$ and b). By contrast, XP-G/CS cells accumulated significant amounts of p53 much earlier, with a $\sim 4$-fold increase at $3 \mathrm{~h}$ and an $\sim 8$-fold increase at $9 \mathrm{~h}$. The level of p53 then reached a plateau that was attained later in XP-G and CS-B cells (Figure $4 a$ and $b$ ). These results demonstrate a rapid and strong accumulation of p53 in XPG-deficient cells, and in particular XP-G/CS fibroblasts, following UV irradiation.

\section{The 90/92 kDa isoforms of the Mdm2 protein do not accumulate in XPG-deficient fibroblasts after UV irradiation}

To investigate possible consequences of this strong p53 accumulation, we analysed fibroblasts for their post-UV
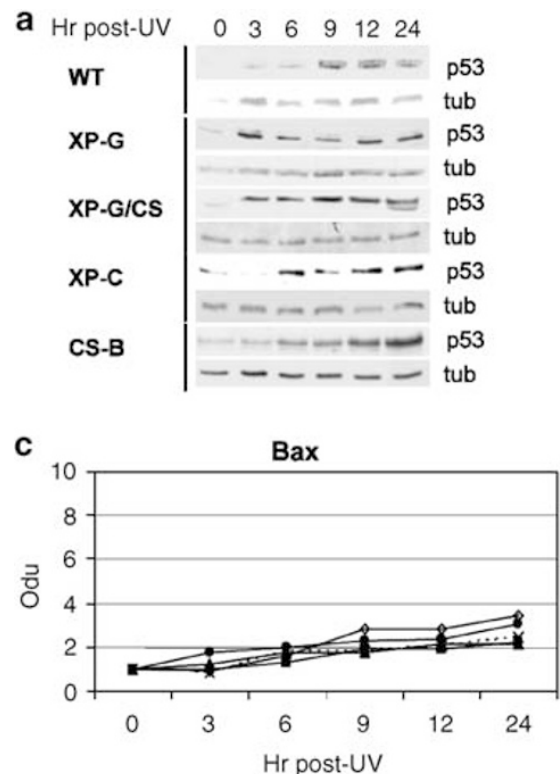

b

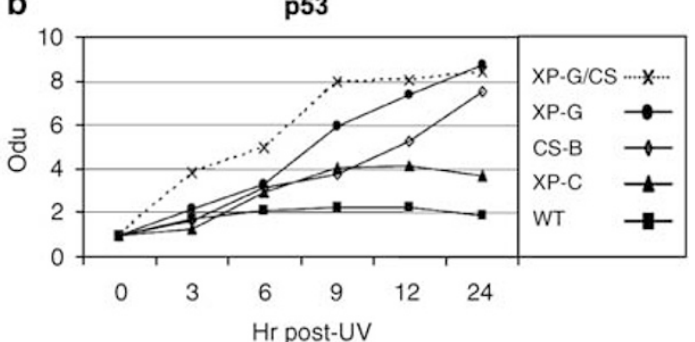

d

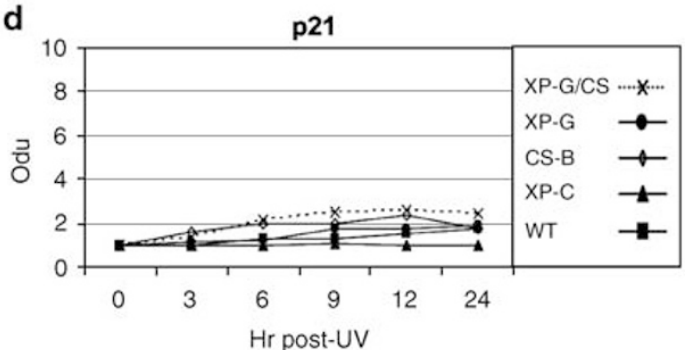

Figure 4 Kinetic examination of p53, Bax and p21 protein levels in UV-irradiated primary fibroblasts. (a) Equal quantities of protein were recovered at various times following a UVC dose of $20 \mathrm{~J} / \mathrm{m}^{2}$ and were analysed by Western blotting with antibodies to p53 and tubulin (as loading control). Quantification of p53 blots (b), and of blots to Bax (c) and p21 (d) was performed with the ChemiDoc ${ }^{\text {TM }}$ system (BioRad) 
expression levels of three proteins, Bax, p21 and Mdm2, whose genes are transcriptionally activated by $p 53 .^{5,6}$ Over a $24 \mathrm{~h}$ period following $20 \mathrm{~J} / \mathrm{m}^{2}$ of UVC, Bax accumulated $<4$ fold in a time-dependent manner in all fibroblasts examined (Figure 4c). Bax accumulation was greatest in CS-B and XP-G cells and least ( $\sim 2$-fold) in wild type, XP-C and XP-G/CS fibroblasts (Figure 4c). Hence, Bax does not seem to play a major role in the highly sensitive UV-induced apoptotic response of XP-G/CS cells (Figure 1).

p21 showed no time-dependent accumulation in XP-C cells and only a modest increase in other repair-deficient and wildtype fibroblasts (Figure 4d). XP-G/CS cells produced the highest p21 levels ( $\sim$-fold increase) that reached a plateau by $9 \mathrm{~h}$ post-UV. p21 may therefore favour the onset of UVinduced apoptosis in these XPG-deficient cells.

The most dramatic differences were found with Mdm2 proteins. Various Mdm2 isoforms exist due to alternative splicing of transcripts from two promoters. ${ }^{19,20}$ Four of these are recognised by the anti-Mdm2 monoclonal antibody 2A10: one isoform of $\sim 46 \mathrm{kDa}$, a second of $\sim 57 \mathrm{kDa}$, a $90 / 92 \mathrm{kDa}$ doublet, and a slower migrating band of $\sim 140 \mathrm{kDa}^{19,21,22}$ The amount of the 90/92 kDa doublet increased significantly in wild-type fibroblasts after a UVC dose of $20 \mathrm{~J} / \mathrm{m}^{2}$. The maximum increase, $\sim 9$-fold, occurred at $9 \mathrm{~h}$ post-UV (Figure $5 \mathrm{a}$ and $\mathrm{c}$ ). XP-C cells exhibited a $\sim 4$-fold increase of the 90/ $92 \mathrm{kDa}$ doublet at 6 and $9 \mathrm{~h}$ post-UV (Figure $5 \mathrm{a}$ and $\mathrm{c}$ ). No major changes were found for the other three Mdm2 isoforms after UV treatment in any of the fibroblasts examined (Figure $5 a$ and b). Strikingly, the 90/92 kDa doublet did not accumulate in XP-G or CS-B cells and showed a $<2$-fold increase in $\mathrm{XP}-\mathrm{G} / \mathrm{CS}$ cells (Figure $5 \mathrm{~b}$ and $\mathrm{c}$ ). These results demonstrate that the $90 / 92 \mathrm{kDa} \mathrm{Mdm2}$ isoforms are not selectively accumulated in either XPG-deficient fibroblasts or, more generally, in cells that are defective in TC-NER.

\section{MDM2 transcripts are made in reduced amounts in TC-NER defective cells}

Immunoblots of wild-type extracts revealed no differences in Mdm2 sumoylation before or after UV irradiation (data not shown). Similarly, extensive incubation with calf intestinal phosphatase had no effect on the migration of the Mdm2 isoforms from wild-type cells treated or untreated with UV (data not shown). This suggests that neither sumoylation ${ }^{23}$ nor phosphorylation ${ }^{24}$ is implicated in the accumulation of the 90/92 kDa Mdm2 isoforms in wild-type and XP-C fibroblasts, or in their failure to be accumulated in TC-NER defective cells (Figure 5).

MDM2 transcripts are generated from a constitutive $\mathrm{P} 1$ promoter and a downstream P2 promoter that is UV inducible. ${ }^{25,26}$ To determine the potential effect of transcriptional regulation on Mdm2 protein accumulation, we examined by quantitative real-time PCR the steady-state levels of the P1 and $\mathrm{P} 2$ transcripts at various times post-UV, using the primers and exon junction TaqMan probes indicated in Figure 6a.

$\mathrm{P} 1$ transcripts remained essentially unchanged for up to $4 \mathrm{~h}$ following a UVC dose of $20 \mathrm{~J} / \mathrm{m}^{2}$. At $24 \mathrm{~h}$ post-UV, they were 3-4-fold more abundant in wild-type and XP-C cells but still unchanged in XPG-deficient and CS cells (Figure 6b).
Consistent with a UV-induced transcriptional activation at the P2 promoter, P2 transcripts strongly accumulated in wildtype cells, being 10-fold more abundant than normal at $24 \mathrm{~h}$ post-UV (Figure 6c). P2 transcripts were found in comparable amounts in UV-irradiated XP-C fibroblasts, whereas no such accumulation occurred in XP-G or XP-G/CS cells (Figure $6 \mathrm{c}$ ). However, CS cells showed a 5-8-fold increase in steady-state P2 RNA levels at $24 \mathrm{~h}$ post-UV (Figure $6 \mathrm{c}$ ), and the $90 / 92 \mathrm{kDa}$ Mdm2 isoforms accumulated from 32-36 h post-UV in CS-B fibroblasts but not in XP-G or XP-G/CS cells (data not shown).

The failure of the $90 / 92 \mathrm{kDa}$ isoforms of $\mathrm{Mdm} 2$ to accumulate in XPG-deficient cells after UV irradiation may thus be related to a lack of transcriptional activation of the MDM2 gene, particularly at its P2 promoter. Alternatively, the
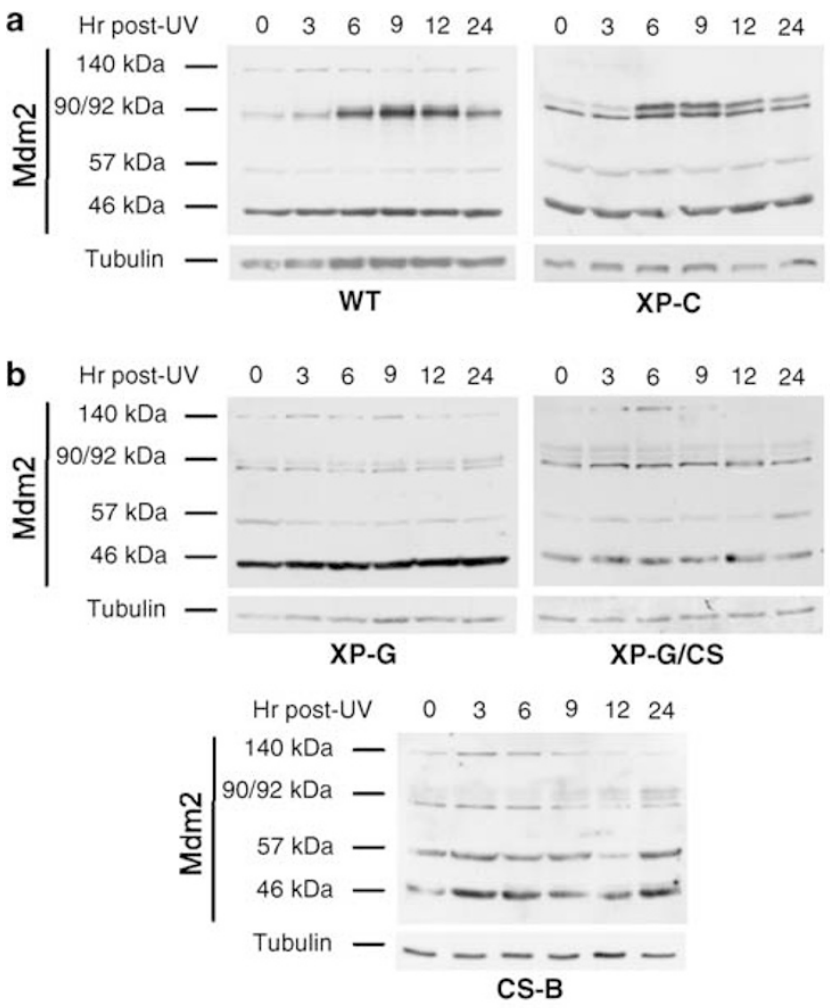

C

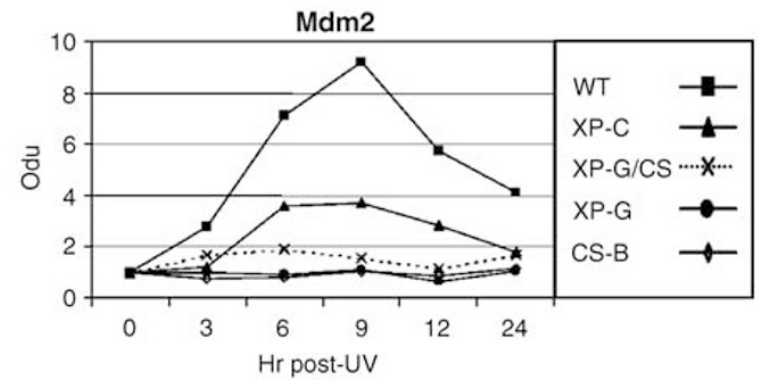

Figure 5 The post-UV accumulation of the $90 / 92 \mathrm{kDa}$ isoforms of Mdm2 is impaired in XPG- and CSB-deficient fibroblasts. Equal quantities of protein were recovered at various times following a UVC dose of $20 \mathrm{~J} / \mathrm{m}^{2}$ and were analysed by Western blotting with antibodies to Mdm2 and tubulin. Blots of wild type and XP-C (a), XP-G, XP-G/CS and CS-B extracts (b) were quantified with the ChemiDoc $^{\mathrm{TM}}$ system (BioRad). (c) Quantification of post-UV Mdm2 $90 / 92 \mathrm{kDa}$ levels 
reduced amounts of $M D M 2$ transcripts found post-UV in XP-G and XP-G/CS cells might reflect their inability to repair transcription blocking lesions. We think, the latter is improbable because a UVC dose of $20 \mathrm{~J} / \mathrm{m}^{2}$ is unlikely to generate sufficient lesion density in the small regions of the gene examined. In addition, TC-NER defective CS cells do accumulate $\mathrm{P} 2$ transcripts post-UV, but later than in wild-type or XP-C fibroblasts. Hence, with respect to MDM2 transcripts too, CS and XPG-deficient cells respond differently to UV irradiation.

\section{XPG restores normal accumulation of the 90/ $92 \mathrm{kDa}$ Mdm2 isoforms after UV irradiation}

To determine if the changes in Mdm2 accumulation reflect the presence or absence of XPG, we transduced wild-type and
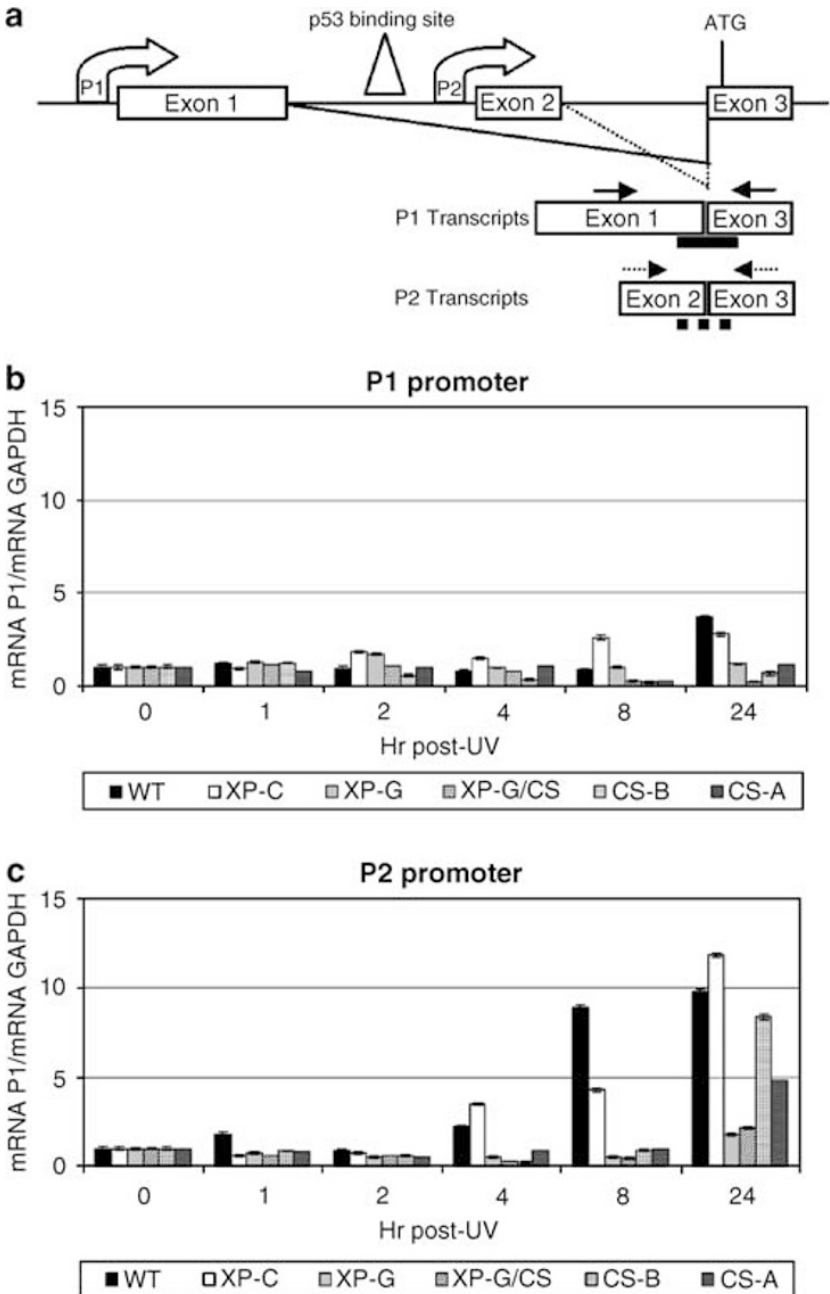

Figure 6 Post-UV accumulation of MDM2 transcripts is inhibited in XPGdeficient cells and delayed in CSB-deficient cells. (a) Strategy for detecting spliced variants of MDM2 transcripts by real-time PCR. Spliced transcripts from the $\mathrm{P} 1$ and $\mathrm{P} 2$ promoters can be distinguished with specific primers (arrows) and the TaqMan probes (thick line) indicated by continuous and dashed lines, respectively. Total RNA was recovered at various times following a UVC dose of $20 \mathrm{~J} / \mathrm{m}^{2}$, subjected to real-time PCR, and the data were normalised and quantified for transcripts from the P1 (b) and P2 promoters (c)
XP-G/CS fibroblasts with lentiviral XPG recombinants or the vector alone and then examined Mdm2 and p53 levels at various times after a $20 \mathrm{~J} / \mathrm{m}^{2}$ UVC treatment.

Normal cells transduced with the empty vector accumulated both $\mathrm{p} 53$ and the $90 / 92 \mathrm{kDa}$ Mdm2 isoforms within $8 \mathrm{~h}$ post-UV (Figure 7a), showing that transduction did not disturb the wildtype expression profiles of these proteins. XP-G/CS fibroblasts transduced with the empty vector showed an even stronger and more persistent accumulation of $\mathrm{p} 53$, but no accumulation of the $90 / 92 \mathrm{kDa}$ Mdm2 isoforms (Figure $7 \mathrm{~b}$ ). By contrast, both p53 and the $90 / 92 \mathrm{kDa}$ Mdm2 isoforms accumulated in XP-G/CS transductants expressing wild-type XPG protein (Figure $7 \mathrm{~b}$ ), and at levels comparable to those found in wild-type cells transduced with the empty vector (Figure 7a). XPG complementation thus restores not only resistance to apoptosis (Figure 2) but also the expression profiles of p53 and Mdm2 following UV stress (Figure 7b).

Transductants expressing the E791A XPG catalytic site mutant behaved differently. One effect of this mutant was the accumulation in both wild-type and XP-G/CS transductants of the $46 \mathrm{kDa}$ Mdm2 isoform (Figure 7). p53 accumulated to a somewhat greater extent than in wild-type XPG transductants but the $90 / 92 \mathrm{kDa}$ Mdm2 isoforms did not accumulate post-UV (Figure 7b). Indeed, E791A XPG inhibited the accumulation of these Mdm2 isoforms when expressed in wild-type cells (Figure 7a).
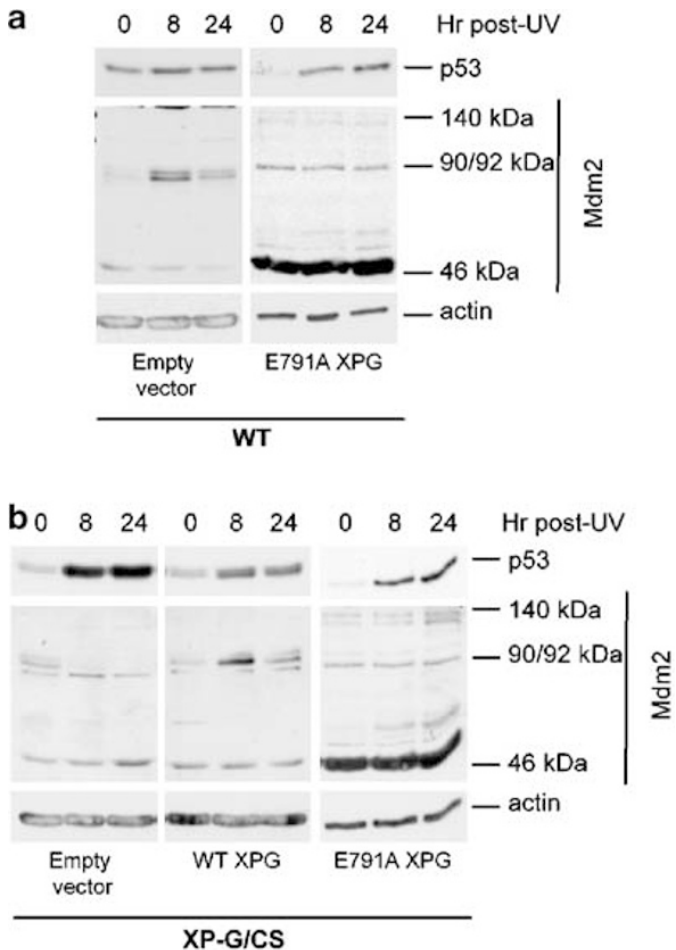

Figure 7 Wild-type XPG, but not the E791A catalytic site mutant, restores accumulation of the Mdm2 $90 / 92 \mathrm{kDa}$ isoforms in transduced XP-G/CS cells. Wild-type (a) and XP-G/CS (b) fibroblasts were transduced with the indicated lentiviral constructs. Equal quantities of protein were recovered at various times following a UVC dose of $20 \mathrm{~J} / \mathrm{m}^{2}$ and were analysed by Western blotting with antibodies to p53, Mdm2 and actin (as loading control) 


\section{Mdm2 does not regain the nucleus of XP-G/CS cells after UV irradiation}

Given these changes in Mdm2 protein levels, we wondered if there were also changes in Mdm2 subcellular localisation after UV treatment. We therefore irradiated wild-type and XP-G/CS fibroblasts with $20 \mathrm{~J} / \mathrm{m}^{2}$ UVC, fixed the cells at various times thereafter, then determined the location of Mdm2 by immunofluorescence.

Immediately following UV treatment and as in unirradiated cells, Mdm2 was found in the nucleus in repair-proficient and repair-deficient cells. At $6 \mathrm{~h}$ post-UV, the staining became diffuse and Mdm2 was present in both the nucleus and cytoplasm of both cell types (Figure $8 \mathrm{a}$ ). By $12 \mathrm{~h}$ post-UV, Mdm2 was exclusively nuclear again in wild-type fibroblasts. By contrast, in XP-G/CS cells the Mdm2 pattern remained diffuse at both 12 and $24 \mathrm{~h}$ post-UV and Mdm2 was mostly confined to the cytoplasm (Figure 8a).

\section{XPG restores normal Mdm2 nuclear localisation after UV irradiation}

To determine if this aberrant Mdm2 subcellular localisation reflects the absence of XPG from the XP-G/CS fibroblasts, we transduced these and wild-type cells with the lentiviral constructs used earlier (Figure 7) and determined the location of XPG and Mdm2 immediately after a $20 \mathrm{~J} / \mathrm{m}^{2}$ UVC treatment and $24 \mathrm{~h}$ later.

Transduction with the empty vector had no effect on Mdm2 localisation. It remained nuclear in wild-type fibroblasts and displayed a diffuse pattern in XP-G/CS cells (compare Figure $8 a-c$ ). By contrast, Mdm2 (red) was found in the nucleus together with XPG (green) $24 \mathrm{~h}$ post-UV in XP-G/CS cells transduced with the wild-type XPG lentiviral construct (Figure 8c). Nuclear localisation of Mdm2 was not observed in XP-G/CS cells transduced with the E791A XPG lentiviral construct (Figure $8 \mathrm{c}$ ). Moreover, wild-type cells expressing this catalytic site mutant also showed a diffuse nuclear and cytoplasmic Mdm2 distribution (Figure 8b). These results thus demonstrate that wild-type XPG is needed for the normal nuclear localisation of Mdm2, and that a catalytic site mutant of XPG can have a dominant negative effect on Mdm2 localisation.

\section{Discussion}

\section{Apoptosis in XPG-deficient fibroblasts}

We report here the first examination of UV-induced apoptosis in primary fibroblasts from XP-G and XP-G/CS individuals. In several respects, the results agree with previous studies of apoptosis in other NER-deficient cells. In particular, fibroblasts with a mutated or absent XPC protein respond to UV like wild-type cells (Figure 1), consistent with the idea that apoptosis is not provoked by a failure to repair UV damage in transcriptionally silent regions of the genome or in the nontranscribed strand of active genes. The higher apoptotic levels found in CS-A, CS-B and XP-A cells (Figure 1) support the corollary, namely that UV-induced apoptosis is somehow related to defective TC-NER. ${ }^{11,16,18,27,28}$ XP-G fibroblasts, which are severely impaired in both NER and TC-NER, respond to UV like XP-A cells (Figure 1). Their behaviour is thus consistent with these propositions. Interestingly, CS cells are very sensitive to a UV-mimetic bulky adduct but this is not due to defective TC-NER. ${ }^{29}$ One novel result documented here is that some XP-G/CS fibroblasts are much more susceptible to UV-induced apoptosis than any other DNA repair-deficient cells examined (Figure 1). This strongly suggests that the apoptotic response of these XP-G/CS cells is also due to more than a defect in TC-NER.

The most susceptible fibroblasts come from XP20BE, an XP-G/CS boy, who encoded severely truncated XPG proteins of 10 and 137 amino acids, compared to full-length XPG of 1186 amino acids $^{30}$ (and A Pigni, unpublished). The other XP$\mathrm{G} / \mathrm{CS}$ cells examined are from XPCS2RO who made a protein of 980 amino acids from both XPG alleles ( $\mathrm{F}$ Thorel, unpublished). The mildly affected XP-G individuals XP65BE and XP125LO encode full-length XPG from one allele but with single amino-acid substitutions that affect XPG endonuclease function. $^{8}$ The A792V substitution in XP125LO has a destabilising affect on XPG, resulting in a steady-state level that is $\sim 20 \%$ of normal (Figure 2 ). These genetic and protein stability considerations are relevant to the similar apoptotic response of XPCS2RO and the two XP-G cells, which is much less severe than that of XP20BE cells (Figure 1). Together, they suggest that very high levels of UV-induced apoptosis result from the absence of XPG, whereas this can be partially alleviated by the presence of low levels of mutated full-length or almost full-length XPG.

\section{p53 and Mdm2 changes in XPG-deficient fibroblasts}

The time-dependent accumulation of p53 in UV-treated XPGdeficient fibroblasts (Figure 4) supports the view that p53 induction is a general feature of human cells following UV stress. Despite this common response, UV-induced apoptosis is not p53-dependent in some primary human fibroblasts. ${ }^{10,17,31,32}$ Whether p53 is required for UV-induced apoptosis in XPG-deficient cells is the subject of a subsequent manuscript (Clément et al., in preparation).

Once induced, p53 transcriptionally activates several downstream genes, including $B A X, p 21$ and $M D M 22^{5,6}$ XPGdeficient cells exhibit only small changes in Bax and p21 protein levels after UV irradiation (Figure 4), but a striking response is their failure to stabilise the $90 / 92 \mathrm{kDa}$ isoforms of Mdm2 (Figure 5). This is consistent with much evidence that Mdm2 acts in a negative feedback loop to downregulate p53 through promoting its proteasomal degradation. ${ }^{4}$ This result further suggests that the $90 / 92 \mathrm{kDa}$ isoforms of Mdm2 are particularly important in this feedback loop, and that failure to stabilise these Mdm2 isoforms permits p53 to accumulate in higher amounts and for longer than normal in XPG-deficient cells.

Mdm2 accumulates normally in XP-C fibroblasts, but not in CS-B cells, after UV irradiation. ${ }^{18}$ The results presented here confirm and extend these observations by showing that it is the $90 / 92 \mathrm{kDa}$ Mdm2 isoform that accumulate preferentially in wild-type and XP-C fibroblasts, but not in CS-B cells (Figure 5). 
a
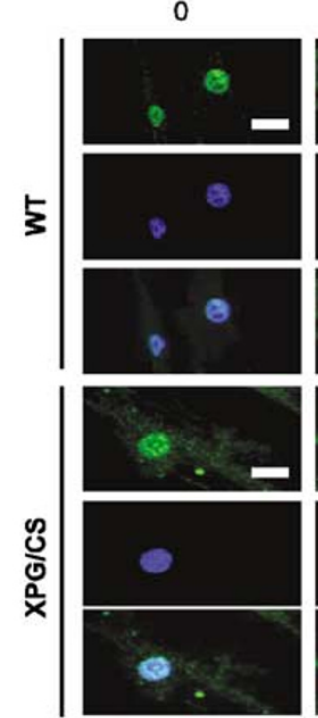

b

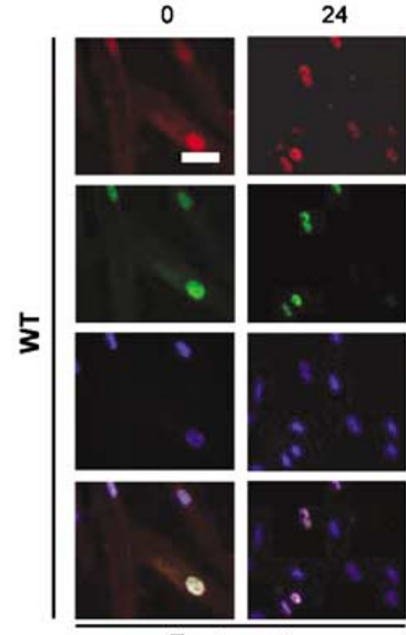

Empty vector

C

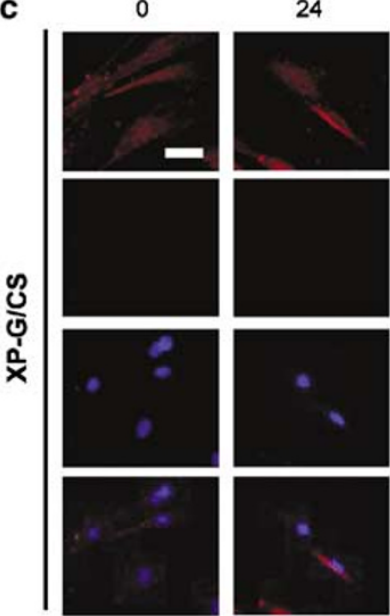

Empty vector
6
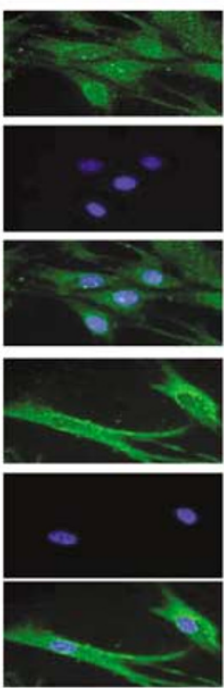

24
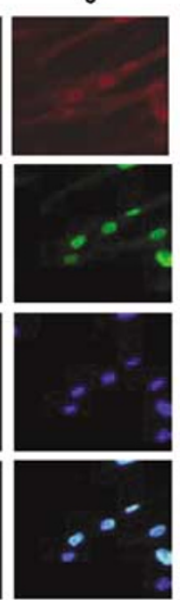

E791A XPG

24
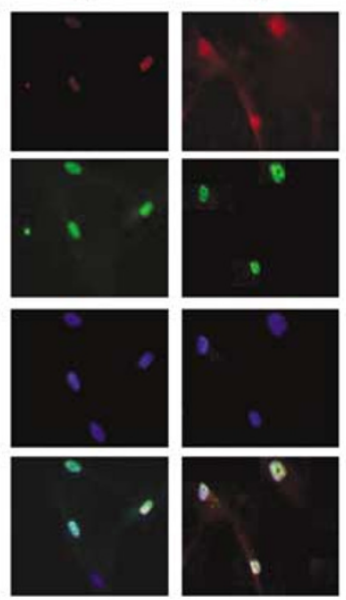

WT XPG
24
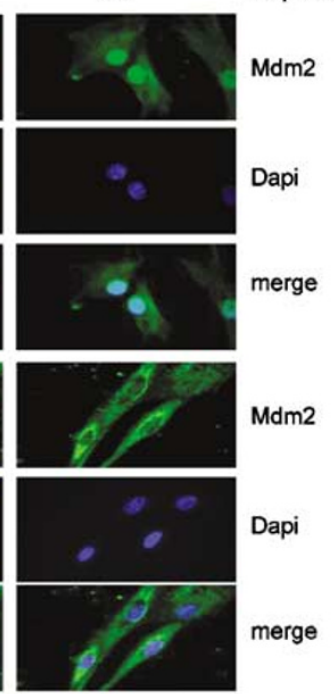

24

Hr post-UV
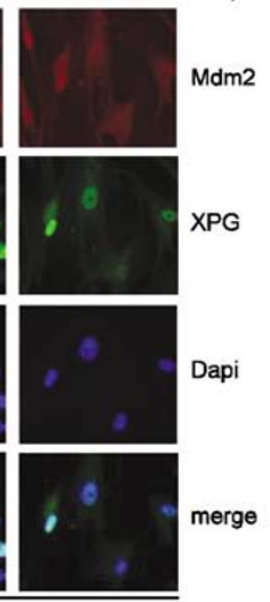

merge

Figure 8 Wild-type XPG, but not the E791A catalytic site mutant, restores the normal post-UV nuclear localisation of Mdm2 in transduced XP-G/CS cells. (a) Subcellular localisation of Mdm2 (green) in wild-type and XP-G/CS fibroblasts at various times following a UVC dose of $20 \mathrm{~J} / \mathrm{m}^{2}$. Nuclei were stained with DAPI (blue). Scale bar, $30 \mu \mathrm{m}$. Wild-type (b) and XP-G/CS (c) fibroblasts were transduced with the indicated lentiviral constructs, and the subcellular locations of Mdm2 (red) and XPG (green) were determined immediately after a UVC dose of $20 \mathrm{~J} / \mathrm{m}^{2}$ and $24 \mathrm{~h}$ later. Nuclei were stained with DAPI (blue). Scale bar, $100 \mu \mathrm{m}$ 
Mdm2 also fails to accumulate post-UV in CS-A and XP-A cells, implying that this response is related to an inability to carry out TC-NER. ${ }^{18,26}$ However, as shown here, not all TCNER defective cells respond to UV irradiation in the same way. MDM2 transcripts, particularly those from the P2 promoter, fail to accumulate in XPG-deficient cells post-UV treatment whereas they do accumulate, albeit later than normal, in CS-A and CS-B cells (Figure 6).

Another striking change in XPG-deficient fibroblasts is the failure of Mdm2 to regain the nucleus soon after UV irradiation. Instead it exhibits a diffuse pattern over the nucleus and cytoplasm (Figure 8). This immunofluorescence study is unable to identify the locations of particular Mdm2 isoforms, but, because the $90 / 92 \mathrm{kDa}$ isoforms are not accumulated in XP-G/CS cells, it seems likely that it is these isoforms that are largely responsible for the strong nuclear Mdm2 signal in wild-type cells. This is consistent with evidence suggesting that different Mdm2 isoforms have different subcellular locations, and perhaps also different functions. ${ }^{33}$

\section{Complementation of XPG-deficient fibroblasts}

It is difficult to compare cellular responses from different repair-deficient patients due to their disparate geographical and genetic backgrounds, including an estimated $\sim 2$ million single nucleotide polymorphic differences between any two unrelated individuals (http://www.genome.utah.edu/geneSNPs/). Fortunately, a complementation approach allows the effects of a particular gene to be assessed in an isogenic context. For primary cells the options are limited to microinjection or viral transduction. In this study, we used lentiviral recombinants to express physiological levels of wild-type XPG in XP-G/CS primary fibroblasts. Such transductants exhibit wild-type levels of UV-induced apoptosis (Figure 2), thereby leading to the important conclusion that the human XPG protein normally suppresses UV-induced apoptosis. Complementation with wild-type XPG also reverses two other major effects of UV irradiation: the $90 / 92 \mathrm{kDa}$ Mdm2 isoforms accumulate normally in such transductants (Figure 7), and these cells exhibit a preferential nuclear localisation of Mdm2 (Figure 8).

None of these effects is observed, however, when XP-G/CS cells express physiological levels of the E791A XPG catalytic site mutant (Figures 2, 7, 8). Although inactive as an endonuclease, this mutant behaves like wild-type XPG in other contexts. It is correctly positioned in the NER preincision complex and permits XPF-ERCC 1 to cut $5^{\prime}$ to the DNA lesion, ${ }^{12}$ and it also stimulates the activity of the DNA glycosylase-AP lyase NTH1 in a reconstituted base excision repair reaction. ${ }^{34}$ These positive results contrast with the negative effects of the E791A mutant on UV-induced apoptosis. It would seem simplest to suggest that the endonuclease function of XPG is needed for wild-type levels of apoptosis, Mdm2 accumulation and subcellular localisation. This might imply that the cells most susceptible to UV-induced apoptosis retain most unrepaired DNA damage, but this is not borne out by immunoslot blot analysis. In particular, the levels of CPDs and 6-4PPs in the highly sensitive fibroblasts from XP-G/CS patient XP20BE are similar to those found in less severely affected XP-G cells (Figure 3). The possibility thus remains that the E791A aminoacid substitution exerts its effect through disrupting an important protein-protein interaction rather than the endonuclease function per se.

\section{XP/CS and other XPG functions}

The results presented here demonstrate that, rather than being a component of a p53-mediated apoptosis pathway, XPG normally acts to suppress UV-induced apoptosis. The results further indicate that defects in TC-NER, or in NER in general, cannot account for the exquisite sensitivity of some XP-G/CS primary fibroblasts to UV-induced apoptosis. Rather, they suggest that these effects are due to disruption of another important XPG function.

The initial proposal of a second XPG function was based on a common mutational pattern in XP-G/CS individuals that results in severely truncated and/or unstable XPG proteins. ${ }^{8}$ Consistent with this suggestion, $\mathrm{Xpa}^{-1-}$ mice have a normal lifespan whereas $\mathrm{Xpg}^{-1-}$ die prematurely, even though they are no more NER defective. ${ }^{8,13}$ Mice with point mutations that inactivate XPG endonuclease activity live normally, whereas a severe XPG truncation leads to early death. ${ }^{13} \mathrm{~A}$ short C-terminal XPG truncation when combined with the Xpa-null allele leads to CS-like symptoms. Hence, the C-terminus may be particularly important for a second XPG function, perhaps only in vertebrates. ${ }^{35}$

There is no shortage of possibilities for other XPG functions. ${ }^{8}$ In particular, XPG has been implicated in transcription by RNA polymerases I and $\|^{36,37}$ and in the recruitment of the PC4 transcription factor to DNA lesions. ${ }^{38}$ A future challenge is to determine if disruption of any of these possible XPG functions contributes to the dramatic UV-induced apoptosis reported here.

\section{Materials and Methods}

\section{Cell strains and culture}

The human 293T cell line and fibroblasts were cultured as described. ${ }^{39}$ The primary fibroblasts used were AG08803 and 96RD29 (from XP-G/CS patients XP20BE and XPCS2RO, respectively), XP125LO and GM01638 (from XP-G patients XP125LO and XP65BE, respectively), GM01630 (XP-A), GM00671 (XP-C), GM02965 (CS-A), GM01428 (CS-B) and 250BR (wild type). All experiments were carried out with primary fibroblasts at passage number $<20$.

\section{Detection of UV-induced apoptosis}

Fibroblasts were irradiated at $254 \mathrm{~nm}$ at a UV fluence of $1 \mathrm{~J} / \mathrm{m}^{2} / \mathrm{s}$ as described. ${ }^{39}$ They were stained with annexinV-FITC and PI (Apoptosis detection kit FITC, Alexis Biochemicals) following the manufacturer's instructions and analysed on a FACScan (Becton Dickinson).

\section{Cell transduction with lentiviral constructs}

Lentiviruses containing an empty vector or wild-type or mutant XPG CDNAs under the control of the EF1 $\alpha$ promoter were produced by transient cotransfection of three plasmids into $293 \mathrm{~T}$ cells as described. ${ }^{39}$ The vector 
was pWIR8 that contains mouse CD8 cDNA as selectable marker. Details of lentiviral vectors and protocols can be found on http://www.tronolab. com. For transduction, infectious viral supernatant was added two times to primary fibroblasts. They were then washed and cultured for $\geq 10$ days. CD8 expression was analysed by flow cytometry (FACScan, Becton Dickinson) after staining with a rat anti-mouse CD8a-PE (Caltag Laboratories). XPG was detected in $150 \mu \mathrm{g}$ of total protein by Western blotting, with tubulin as loading control.

\section{Detection of CPDs and 6-4PPs by immunoslot blot analysis}

Fibroblasts were irradiated and pelleted at different times post-UV. DNA was isolated using the DNeasy tissue kit (Qiagen) according to the manufacturer's instructions. Heat-denatured DNA samples (400 ng) were then blotted onto a nitrocellulose membrane $(0.1 \mu \mathrm{m}$ pore size, Schleicher \& Schuell) and subjected to immunoslot blot analysis. ${ }^{14}$ CPDs and 6-4PPs were detected using the mouse monoclonal $\mathrm{H} 3$ and $64 \mathrm{M}-2$ antibodies, respectively (gifts from $O$ Nikaido). Detection was performed using horseradish peroxidase (HRP)-conjugated anti-mouse IgGs (Promega) and chemiluminescence visualisation (ECL, Amersham).

\section{Western blot analysis}

Cell pellets were lysed on ice for $30 \mathrm{~min}$ in $50 \mathrm{mM}$ Tris- $\mathrm{HCl}(\mathrm{pH} 7.5), 1 \mathrm{mM}$ EDTA, $25 \mathrm{mM} \mathrm{NaCl}, 0.1 \%$ Triton $\mathrm{X}-100$ and protease inhibitor cocktail (Roche Diagnostics). Equal amounts of proteins were electrophoresed through denaturing polyacrylamide gels and were transferred by bidirectional diffusion overnight at $50^{\circ} \mathrm{C}$ onto two nitrocellulose membranes. ${ }^{40}$ Membranes were probed with the following antibodies: mouse monoclonal anti-p53 (D0-1, Santa Cruz Biotechnology) at 1:2000, mouse monoclonal anti-Mdm2 (2A10, Oncogene) at $1.5 \mu \mathrm{g} / \mathrm{ml}$, rabbit polyclonal anti-p21 (N-20, Santa Cruz Biotechnology) at $1: 600$, mouse monoclonal anti-Bax (B-9, Santa Cruz Biotechnology) at $1.5 \mu \mathrm{g} / \mathrm{ml}$, mouse monoclonal anti-tubulin (B-5-1-2, Sigma) at $1: 10000$, mouse monoclonal anti-actin (C4, Chemicon International, Inc) at 1:5000. As secondary antibodies, HRP-conjugated anti-mouse or anti-rabbit IgGs (Promega) were used at $1: 4000$. Proteins were detected using chemiluminescence (ECL, Amersham) and quantified using the ChemiDoc ${ }^{\mathrm{TM}}$ system with Quantity One software (BioRad). All results were normalised with respect to the internal control (tubulin or actin), and were expressed relative to the levels found in cells immediately after irradiation or in unirradiated cells.

\section{Real-time PCR}

Total RNA was prepared using the RNeasy kit (Qiagen). cDNA was synthesised from $1 \mu \mathrm{g}$ of total RNA using random hexamers and Expand Reverse Transcriptase (Roche Diagnostics). Real-time PCR was performed using the TaqMan sequence detection system (Applied Biosystems). PrimerExpress software was used to design the following primers and TaqMan probes for the detection of spliced transcripts from the MDM2 P1 or P2 promoters. For spliced mRNA from P1: forward $5^{\prime}-\mathrm{CT}$ CCAAGCGCGAAAACC-3' ${ }^{\prime}$, reverse $5^{\prime}$-GTTACAGCACCATCAGTAGGTA CAGAC- $3^{\prime}$ and probe $5^{\prime}$-TGCACATTTGCCTGCTCCTCACCA-3'. For spliced mRNA from P2: forward 5'-ACGGACGCACGCCACT-3', reverse 5'- GTTACAGCACCATCAGTAGGTACAGAC-3' and probe 5'-CTCTGCT GATCCAGGCAAATGTGCA-3'. A primer-probe combination for GAPDH mRNA was used as an internal control (Applied Biosystems). Samples were quantified using relative standard curves for each amplification. All results were normalised with respect to the internal control, and were expressed relative to the levels found in unirradiated cells. Experiments were performed in duplicate three times.

\section{Immunofluorescence}

Immunofluorescence was carried out as described ${ }^{39}$ but with mouse monoclonal antibodies to Mdm2 (2A10, Oncogene) at $1 \mu \mathrm{g} / \mathrm{ml}$, and to XPG $(8 \mathrm{H} 7$, gift from RD Wood) at 1:100. Detection was performed with the anti-mouse $\lg \mathrm{G}(\mathrm{H}+\mathrm{L})$ Alexa $^{\mathrm{TM}} 488$ (green) or 568 (red) conjugates (Molecular Probes) at 1:400. Nuclear staining was performed using DAPI (Molecular Probes) at 1:300. Stained cells were observed by Zeiss Axiocam microscopy with Axiovision ${ }^{\mathrm{TM}}$ software.

\section{Acknowledgements}

We are very grateful to $P$ Lalle for helpful discussions and to $O$ Nikaido and RD Wood for gifts of antibodies. This work was supported by Swiss National Science Foundation Grant 3100A0-100487 and the 'Frontiers in Genetics' NCCR program.

\section{References}

1. Hoeijmakers JH (2001) Genome maintenance mechanisms for preventing cancer. Nature 411: 366-374

2. Ljungman M and Lane DP (2004) Transcription - guarding the genome by sensing DNA damage. Nat. Rev. Cancer 4: 727-737

3. Mellon I (2005) Transcription-coupled repair: a complex affair. Mutat. Res., in press

4. Michael D and Oren M (2003) The p53-Mdm2 module and the ubiquitin system. Semin. Cancer Biol. 13: 49-58

5. Meek DW (2004) The p53 response to DNA damage. DNA Repair (Amsterdam) 3: 1049-1056

6. Harms K, Nozell S and Chen X (2004) The common and distinct target genes of the p53 family transcription factors. Cell. Mol. Life Sci. 61: 822-842

7. Lehmann AR (2003) DNA repair-deficient diseases, xeroderma pigmentosum, Cockayne syndrome and trichothiodystrophy. Biochimie 85: 1101-1111

8. Clarkson SG (2003) The XPG story. Biochimie 85: 1113-1121

9. Wang XW, Vermeulen W, Coursen JD, Gibson M, Lupold SE, Forrester K, Xu G, Elmore L, Yeh H, Hoeijmakers JH and Harris CC (1996) The XPB and XPD DNA helicases are components of the p53-mediated apoptosis pathway. Genes Dev. 10: 1219-1232

10. McKay BC, Becerril C and Ljungman M (2001) P53 plays a protective role against UV- and cisplatin-induced apoptosis in transcription-coupled repair proficient fibroblasts. Oncogene 20: 6805-6808

11. Queille S, Drougard C, Sarasin A and Daya-Grosjean $L$ (2001) Effects of XPD mutations on ultraviolet-induced apoptosis in relation to skin cancer-proneness in repair-deficient syndromes. J. Invest. Dermatol. 117: 1162-1170

12. Constantinou A, Gunz D, Evans E, Lalle P, Bates PA, Wood RD and Clarkson SG (1999) Conserved residues of human XPG protein important for nuclease activity and function in nucleotide excision repair. J. Biol. Chem. 274: 5637-5648

13. Thorel F, Constantinou A, Dunand-Sauthier I, Nouspikel T, Lalle P, Raams A, Jaspers NG, Vermeulen W, Shivji MK, Wood RD and Clarkson SG (2004) Definition of a short region of XPG necessary for TFIIH interaction and stable recruitment to sites of UV damage. Mol. Cell. Biol. 24: 10670-10680

14. Smit NP, Vink AA, Kolb RM, Steenwinkel MJ, van den Berg PT, van Nieuwpoort $F$, Roza L and Pavel S (2001) Melanin offers protection against induction of cyclobutane pyrimidine dimers and 6-4 photoproducts by UVB in cultured human melanocytes. Photochem. Photobiol. 74: 424-430

15. Mitchell DL, Haipek CA and Clarkson JM (1985) (6-4)Photoproducts are removed from the DNA of UV-irradiated mammalian cells more efficiently than cyclobutane pyrimidine dimers. Mutat. Res. 143: 109-112

16. Ljungman $M$ and Zhang $F$ (1996) Blockage of RNA polymerase as a possible trigger for u.v. light-induced apoptosis. Oncogene 13: 823-831 
17. McKay BC and Ljungman M (1999) Role for p53 in the recovery of transcription and protection against apoptosis induced by ultraviolet light. Neoplasia 1: 276-284

18. Conforti G, Nardo T, D'Incalci M and Stefanini M (2000) Proneness to UVinduced apoptosis in human fibroblasts defective in transcription coupled repair is associated with the lack of Mdm2 transactivation. Oncogene 19: 2714-2720

19. Olson DC, Marechal V, Momand J, Chen J, Romocki C and Levine AJ (1993) Identification and characterization of multiple mdm-2 proteins and mdm-2-p53 protein complexes. Oncogene 8: 2353-2360

20. Barak Y, Gottlieb E, Juven-Gershon T and Oren M (1994) Regulation of mdm2 expression by $p 53$ : alternative promoters produce transcripts with nonidentical translation potential. Genes Dev. 8: 1739-1749

21. Bottger A, Bottger V, Sparks A, Liu WL, Howard SF and Lane DP (1997) Design of a synthetic Mdm2-binding mini protein that activates the p53 response in vivo. Curr. Biol. 7: 860-869

22. Haupt Y, Maya R, Kazaz A and Oren M (1997) Mdm2 promotes the rapid degradation of p53. Nature 387: 296-299

23. Miyauchi Y, Yogosawa S, Honda R, Nishida T and Yasuda H (2002) Sumoylation of Mdm2 by protein inhibitor of activated STAT (PIAS) and RanBP2 enzymes. J. Biol. Chem. 277: 50131-50136

24. Blattner C, Hay T, Meek DW and Lane DP (2002) Hypophosphorylation of Mdm2 augments p53 stability. Mol. Cell. Biol. 22: 6170-6182

25. Saucedo LJ, Carstens BP, Seavey SE, Albee II LD and Perry ME (1998) Regulation of transcriptional activation of mdm2 gene by p53 in response to UV radiation. Cell Growth Differ. 9: 119-130

26. Michalowski J, Seavey SE, Mendrysa SM and Perry ME (2001) Defects in transcription coupled repair interfere with expression of p90(MDM2) in response to ultraviolet light. Oncogene 20: 5856-5864

27. Yamaizumi M and Sugano T (1994) U.V.-induced nuclear accumulation of p53 is evoked through DNA damage of actively transcribed genes independent of the cell cycle. Oncogene 9: 2775-2784

28. Ljungman M, Zhang F, Chen F, Rainbow AJ and McKay BC (1999) Inhibition of RNA polymerase II as a trigger for the p53 response. Oncogene 18: 583-592

29. van Oosterwijk MF, Versteeg A, Filon R, van Zeeland $A A$ and Mullenders $L H$ (1996) The sensitivity of Cockayne's syndrome cells to DNA-damaging agents is not due to defective transcription-coupled repair of active genes. Mol. Cell. Biol. 16: 4436-4444

30. Okinaka RT, Perez-Castro AV, Sena A, Laubscher K, Strniste GF, Park MS, Hernandez R, Maclnnes MA and Kraemer KH (1997) Heritable genetic alterations in a xeroderma pigmentosum group G/Cockayne syndrome pedigree. Mutat. Res. 385: 107-114

31. Wani MA, Zhu QZ, El-Mahdy M and Wani AA (1999) Influence of p53 tumor suppressor protein on bias of DNA repair and apoptotic response in human cells. Carcinogenesis 20: 765-772

32. Proietti De Santis L, Balajee AS, Lorenti Garcia C, Pepe G, Worboys AM and Palitti $F$ (2003) Inhibition of p53, p21 and Bax by pifithrin-alpha does not affect UV induced apoptotic response in CS-B cells. DNA Repair (Amsterdam) 2: $891-900$

33. Maxwell SA (1994) Selective compartmentalization of different mdm2 proteins within the nucleus. Anticancer Res 14: 2541-2547

34. Klungland A, Hoss M, Gunz D, Constantinou A, Clarkson SG, Doetsch PW, Bolton P, Wood RD and Lindahl T (1999) Base excision repair of oxidative DNA damage activated by XPG protein. Mol. Cell 3: 33-42

35. Shiomi N, Mori M, Kito S, Harada YN, Tanaka K and Shiomi T (2005) Severe growth retardation and short life span of double-mutant mice lacking Xpa and exon 15 of Xpg. DNA Repair (Amsterdam) 4: 351-357

36. Bradsher J, Auriol J, Proietti de Santis L, Iben S, Vonesch JL, Grummt I and Egly JM (2002) CSB is a component of RNA pol I transcription. Mol. Cell 10: 819-829

37. Lee SK, Yu SL, Prakash L and Prakash S (2002) Requirement of yeast RAD2, a homolog of human XPG gene, for efficient RNA polymerase II transcription. Implications for Cockayne syndrome. Cell 109: 823-834

38. Wang JY, Sarker AH, Cooper PK and Volkert MR (2004) The single-strand DNA binding activity of human PC4 prevents mutagenesis and killing by oxidative DNA damage. Mol. Cell. Biol. 24: 6084-6093

39. Dunand-Sauthier I, Hohl M, Thorel F, Jaquier-Gubler P, Clarkson SG and Scharer OD (2005) The spacer region of XPG mediates recruitment to nucleotide excision repair complexes and determines substrate specificity. J. Biol. Chem. 280: 7030-7037

40. Bowen B, Steinberg J, Laemmli UK and Weintraub H (1980) The detection of DNA-binding proteins by protein blotting. Nucleic Acids Res 8: 1-20 